emphasis on the study of behavior, it seems unfortunate that so much stress should be laid on attempts to prove the psychic nature of "subconscious" activities. We need rather attempts to bring the phenomena in question under experimental control, to describe and classify them, before we set up hypotheses as to their ultimate nature.

University of North Carolina

H. W. Chase

\title{
PSYCHOLOGY AT THE RECENT MEETING OF THE BRITISH ASSOCIATION FOR THE ADVANCEMENT OF SCIENCE (BIRMINGHAM, SEPTEMBER IO-17, I9I3)
}

This year, for the first time, a subsection for psychology was established by the British Association. Hitherto psychological papers have been heard chiefly in the section of Physiology, which is still sponsor for the newly formed subsection. Judging by the large attendance at the meetings, the considerable number of papers, and the interest aroused, it is highly probable that the new division will soon demonstrate its claims to independence.

The meetings occupied five days, and were ably presided over by the chairman of the subcommittee, Prof. J. H. Muirhead, while Mr. Cyril Burt acted as recorder. Plans were laid to continue the subsection at the next meeting, which is to be held in Australia, and it is confidently expected that the I9I 5 meeting at Manchester will be even more successful than the past occasion has been. Two joint meetings were held, one with the section of Physiology and one with the section of Education.

Some thirty-five papers, covering a wide variety of topics, were read. Of these applied psychology had the chief share, with some nineteen titles, of which twelve were in educational psychology.

Among the papers which dealt with general and systematic problems may be mentioned the following: (I) H. Wildon Carr, The Absurdity of Psycho-physiological Parallelism even as an Hypothesis. The speaker's thesis was that since consciousness is not of the nervous processes with which it is correlated, but of the whole physical world which brings about the nervous activities, therefore it is absurd to assume that the part (or cortical processes) is equivalent to the whole physical universe of which consciousness makes us aware. (2) William McDougall, $A$ New Theory of Laughter. 
Laughter is a protective reaction, occasioned by minor distresses which would have a cumulative depressing influence were it not for the acquired capacity to drain off the nervous energy thus aroused through the channels of the laughter reaction. The typical expression of pleasure is not laughter but the smile, which is of a different order and appears earlier in childhood. (3) H. J. Watt, Some Main Principles of Integration. This paper dealt with the possibility of proceeding on the basis of sensation through integrative stages to the higher mental processes. (4) Carveth Read, The Condition of Belief in Immature Minds (Children and "Savages"). The main point of this discussion was that all beliefs have their fundamental ground in perception. The imaginative beliefs arise largely in minds which lack a definite logical test for truth, but it is wrong to suppose that they are as profound as those based upon perception. Their utility has kept them alive, but there is no justification in tracing scientific ideas to them. (5) G. J. Stokes, in his paper on The Relation of the Emotions to Motor Discharge, advanced the theory that the nervous correlate of emotion might be sought in the nervous processes which connect the sensory and motor centers of the cortex.

In the field of experimental psychology, C. S. Myers reported on Experiments in Sound Localization now being conducted in the very carefully constructed sound-proof room of the Cambridge laboratory. Results seem to indicate that the localization of sound in the median (sagittal) plane are, at best, very inaccurate, and that learning to localize is primarily dependent upon loudness and timbre. Tactual impressions felt by the subject upon the face and head appear upon analysis to be illusory. R. M. Ogden reported upon The Spatial Localization of Visual Images. The complete report is published in' the September issue of the Psychological Review. Miss Mary Smith read a paper on Two Forms of Memory and their Relation, which reported a series of experiments undertaken to test the validity of Bergson's distinction of the two types of memory. Five tests were used. Two dealt with mechanical associations in nonsense syllables and motor activities, while three involved recognition, analytic ability and intelligence. A high degree of correlation was established between the tests of each group, while the correlation was low between tests of the two groups.

"Imageless thought" came in for a share of the discussion in the paper of Miss S. S. Fairhurst (read by C. S. Myers) on the Analysis of the Mental Processes Involved in Spelling. Her investigation indicated that "imageless" spelling is an important factor, which 
involves a distinction between the knowledge of the facts of spelling and mere reference to imagery. Also in the paper on the Conditions which Arouse Mental Imagery in Thought, C. Fox reported experiments in which the meaning-process aroused by a series of statements, true and false, was introspected. Mental images were found to be absent in about 50 per cent. of the reports, and when present they seemed to be occasioned by some delay or hindrance in the process. It was of some interest to note that the acceptance of imageless contents appeared to arouse no serious opposition.

The Freudian psychology was debated in connection with a paper on Psycho-Analysis by William Brown, in which the Freudian theory was summarized, and in An Analysis of Some Personal Dreams with Special Reference to Current Theories of Dream Interpretation, by T. H. Pear. The last-named speaker discussed dreams illustrative of the dramatizations, condensations and displacements which the Freudian views have made familiar. A second paper by T. $H$. Pear and one by Stanley Wyatt dealt with the psychology of testimony in normal and defective children.

Among the papers which bore upon educational psychology may be mentioned Miss I. Suddard's Investigation into Spelling in the Fielden Demonstration School, which indicated the appearance of the "spelling disease" with the beginning of free composition, and the possibility of lessening its evil effects by postponing free composition and keeping the work under the teacher's control until proper spelling habits had been formed. Miss S. S. Fairhurst, whose work, mentioned above, formed the basis for two reports, found that the articulation of letters was of no direct aid in spelling, but that the articulation of syllables, which constitute the phonic - units of spelling, when simultaneous with the writing of the word, is probably the best method of learning to spell. Her results indicated further that spelling efficiency is independent of the imaginal type of the speller.

Sir William Ramsay found the occasion of these reports emphasizing the difficulties of learning to spell opportune for a few remarks in support of the English movement to reform spelling by making it phonetic.

C. W. Valentine reported some experiments on the Method of Teaching Reading, which indicated that the phonic method is preferable to the "look and say" method.

E. O. Lewis reported some experiments in learning of unfamiliar words and pictures, which substantiated previous indications that the 
method of learning by wholes is better than that of learning by parts, although in the case of unfamiliar words the syllabic unit was found to be economical.

A mass investigation on Practice Improvement in Immediate Memory in School Children was reported by J. L. McIntyre. The tests were made with meaningless syllables, and the results showed the marked superiority of girls over boys, and of town over country children. It was also shown that a considerable amount of improvement of ability gained by memorizing syllables was available for ordinary school work.

Miss A. L. Rogers reported upon the Application of the BinetSimon Tests to Normal Children in Scotland, which was made in conjunction with Dr. McIntyre. The scale was found to be too easy for the early years and too hard for the later years, but on the whole reliable. More exceptional boys, both gifted and deficient, were found than girls.

R. C. Moore's paper on Tests of Reasoning and their Relation to General Ability (read by C. Burt) and W. H. Winch's paper on Additional Tests for Reasoning Suitable for the Mental Diagnosis of School Children indicated the feasibility of such tests. Mr. Moore's analogies, syllogisms and arguments showed a higher correlation with teachers' estimates than do the average Binet tests, while $\mathrm{Mr}$. Winch's ingenious problems seemed to furnish a natural means of testing reasoning ability unrelated to school work. Mr. Cyril Burt's mass investigation on the Mental Differences between the Sexes indicated that the differences grow progressively slighter as one proceeds from instinctive to acquired capacities. The females showed superiority in skin discrimination, memory, reading, writing and finding opposites; the males in tapping tests, addition, multiplication, argument and syllogistic exercises.

Space permits but brief mention of the remaining papers which were presented. C. W. Valentine reported an ingenious test of Color Perception and Preference in a Three Months Old Infant. Nine colored wools were presented to the child in pairs for two minute intervals and the time in which each color was attended to was recorded. The results indicated the following order of preference: (1) yellow, (2) white and pink, (3) red, (4) brown and black, (5) green and blue, (6) violet. The brightest colors were in general preferred but the marked difference in preference between red, green, blue and violet, all of which were equally bright, is noteworthy.

Godfrey Thompson's paper on Variations in the Spatial Threshold 
reported upon experiments which indicated a sharp fall in the threshold during the first twenty judgments, followed by a slow rise to about forty, after which it became erratic, but often fell again at the end of the sitting. The speaker concluded that the average threshold is a matter of mathematical definition and not a psychological experience: that for psychology no real threshold can be established.

Only one paper was read on animal psychology, $A$ Note on HabitFormation in Guinea Pigs by Miss E. M. Smith, in which the speaker described two tests now being used in the Cambridge laboratory with the aim of studying the inheritability of such characters as learning, practice, accuracy, retentiveness, etc.

Shepherd Dawson's Simple Method of Demonsirating Weber's Law was the only title which suggested the technique of apparatus. Mr. Dawson's method consists in rotating white and gray disks punctured upon a radius with equally sized holes against a black background. - The relative brightness of the rings thus produced tests the law by the simple procedure of counting the number of rings which can be seen on each disk.

A mass investigation on The Relative Fertility and Morbidity of Normal and Defective Stocks showed greater fertility and morbidity for the defective than for the normal stocks.

Two papers bearing upon fatigue were read, by Miss Mary Smith: Some Experiments on Recovery from Fatigue, and by J. H. Wimms: $A$ Comparative Investigation of Fatigue Tests.

Dr. Auden read the report of the Committee of the Education section on The Relation of School Books to Eyesight. The Rev. J. Knowles addressed himself to The Need of a Common Alphabet for the Vernacular Languages of India. A Plea for Research in Education was made by C. W. Kimmins and supported by brief remarks from C. S. Myers, J. J. Findlay, J. A. Green and C. Burt. A paper on The Excessive Use of Suggestion in Education was presented by Mrs. Meredith, while the concluding title of the program was Contrast as a Factor in Psychological Explanation, by W. G. Smith.

R. M. OgDEN

UNIVERSITY OF TENNESSEE 